at all, his body has been consigned to the grave."

There is a case published by Dr. Cheyne, of a man who had the power of suspending his animal functions, and who performed the experiment once too often.*

It may be supposed that the public notice of the extraordinary powers of this man will attract the attention of physiologists in both hemispheres.

*** We copy the foregoing extraordinary, and apparently well-authenticated account, from the Number of the India Medical Journal for Angust, 1836, (edited by $\mathrm{Mr}$. Corbyn), a file of which periodical work, from June, 1836, to Jannary, 1837, we have this week received from Calcutta, where the journal is published. We should state, that we have condensed Mr. Twedell's introductory and closing observations, but without omitting anything which can be regarded as important.-Ev. L.

\section{RESTORATION TO SIGHT OF A YOUTH BORN BLIND.}

CATARACT. OPERATION.

\section{By F. H. Brett, Esq.}

Khundoo, pundit, a native of Saugor, was born blind. His mother kept him in a dark room until the 10th day after her confinement, when on exposing his eyes to the light, she discovered the pearly appearance of the pupils peculiar to cataract. He has always since been blind. He is intelligent and cheerful, and has found his way about Saugor, and the adjoining country, for many years, frequently singing, of which he is very fond. He had no inclination to undergo the operation, through the fear which he entertained. He could perceive the light, and rotated the head constantly to the right and left, with a view, $I$ imagine, of admitting the light to the retina, obliquely between the cataract and the under edge of the iris. He had requested to be taken to me some months previously, on being told that he might be made to see; but the introduction of a few drops of the solution of belladonna under the lids, and my holding the lids to try how they should be supported, annoyed him, and he said he would much sooner go home and eat bis dinner. "What do I want with sight?" His mother likewise disbelieved that a person born blind minht be made to see. The principal pundit of the Mohulea at length overruled the objections.

* This case is described in Professor Thomson's Lecture, in THz LANUET, of Feb. $25,183 \%$, page 772. -ED. L.
The cataract was entirely membranous, studded with pearly spots. The operation was performed on the 28th of August, with a double-edged needle. The cataract, which was very tough, was cut into two or three shreds, and left principally in the anterior chamber, without submitting the delicate organ to much irritation by repeated motions of the instrument. He complained of but little pain, and, indeed, scarcely any inflammation was produced. He immediately became conscious of a considerable increase of light.

The eye-balls in all cases of congenital cataract move about without any control, which, with much spasmodic action of the orbicularis, offered great apparent obstacles to the introduction of the needle, and it was quite impossible to use any speculum, or to support the lids at all. I find in all such cases that it is better to introduce the needle without snpporting the lids, which has an instantaneous effect in keeping the eye-ball steady. The operator can see sufficiently distinctly to direct the needle. The native operators seldom hold the lids in any case.

I operated on this day, the 30th August, on the left eye. No inflammation followed, but the right eye had become inflamed, in consequence of which his eyes remained bandaged for several days, and it became necessary to bleed him, nse counter irritation, purge with calomel and antimony, and apply leeches to the eyebrows. He was sensible of a remarkable change; the light was most distressing to him for some time.

On the 8th day, the absorption having proceeded very satisfactory, several substances, of various colours, were presented to him. He could not recognize any of them until he had touched them. He brought them very close to his eyes, moving his head in his accustomed peculiar manner. Whenever he attempted to reach any thing, he always missed his aim at it. He was highly gratified, and confident that he would know every thing, but did not like too much interrogation.

On the 12th day he came to me again. The eye-balls were no longer rolled about in their formet vacant manner. He bad acquired the powel of directing the left eye on objects. The right eye, from intlammation, remained bandaged. A lady showed him her shawl; he said it was red, which was correct, but did not know what it was, until examined by the hand. The platform in front of the house was recognized as green, and his mother said he had been examining many things at home. The absorption of the cataract had left two-thirds of the pupils of the left eye quite clear. He said he was no longer afraid of me, and that he would submit to any thing I recommended.

On the 16th of Sept. he walked from the town to see me, with his mother. He had 
now gained much information. The pupil of the left eye had become almost clear. He said he had seen a great number of trees on the road, the lake, and a bugry passing by. "What is this ?" I said. "A lota." "This?" "A pawn-leaf." A small hooka was shown to him; he touched it, and was told what it was. Several other things were then presented to him, and then the hooka was again brought. He observed, "I cannot tell what it is; you have submitted so many things to me, that I am confused, and forget their names." He felt it, and then exclaimed "It is the same hooka." Presently it was shown to him a third time; he recognized it after carefully viewing it from top to bottom, without touching it. He observed a bock, remarking that it was red; a table, black and gold; but he knew not that it was a hook until told so. It was presented to him a few minutes afterwards, and he recognized both the colour and the book. He said he was extremely happy, and gratified with all he saw. He followed me with his eyes as I moved about the room, and pointed out the different positions I took. He recog. nized distinctly the features of his mother's face. She hid it under her chudder; he laughed, observed that she had done so, and turned his face array. He said "I can see every thing; all I want more is, time to learn what they all are, and when I can walk about the town I shall be quite satisfied." He could not ascertain whether any thing was round or square, smooth or rough. He distinguished the following:- Some partridges, the cage, and the cup containing the water. The colour of their plumage he correctly stated, also the windows, the fields, the sky, a child in arms, \&c.

On the 17 th he again came to see me. He pointed out every feature in his mother's face, her hair, the colour of her dress, the different distances and positions which she purposely took, and when changing places with another woman he selected her out. He stated, that if $\mathrm{I}$ would bring the red book, he would recognize it. I accordingly brought him a red morocco box, much resemhling the book, but smaller; he said it was the book! At this period his knowledge of the shapes of bodies and their sizes was very imperfect, especially the latter. He directed his hand straight to whatever things were now presented before him. The last time I saw him, a small ivory looking-glass, a paper-cutter, and a cut jelly-glass, were placed on the ground. They were shifted and changed, and he distinguished each respectively. He was much amused, and laughed heartily. I gave him the lookingglass, in which he noticed his face, and said it was like other people's "achcha." At this period I quitted Saugor, and have heard nothing further of him.-India Medical Jour. No. 4, Vol. I., N. S., 1836.
Crfosote, "the new German remedy," has been used on several occasions in the Calcutta General Hospital, in cutaneous diseases. One of the medical officers of that institution thus speaks of its employment:"In three cases of adultring. worm it seemed to do decided good. In two children it effected a speedy cure. In a case of caries of the tooth the relief from one drop was immediate and permanent. In a case of chronic rupia, and one of herpetic scaly dis. ease, dependent on old constitutional de. rangement, it rather did harm. In an irrittable and scrofulous ulcer it allayed irritation, and seemed to act sedatively, like its powerful prototypes, the hydrocyanic acid and lead lotion. Upon the whole, from the result of ten cases, I am disposed to think that this will prove a valuable addition to our Indian medicinals, where skin diseases are so numerous and troublesome; and it may sometimes succeed where all other known agents have failed."

Diagnosis by the Tongue.-In a case of fatal gastro-enteritis in the Calcutta General Hospital, a report of the case in the India Journul contains the following remarks by Dr. Stewart. The patient was "an old soldier, but of immense muscular and bony formation:"-The state of the tongue, the character of the expectoration, the sound of the voice, the colour and appearance and smell of the stools, are the only indications in the treatment. During 24 days that he lived in hospital, a variety of treatment was followed, all unsuccessfully. Emaciation proceeded; nothing like healthy secretion was procured; the tongue became varnished, nay, polished, dry, and bright, like a carriage pannel, and its colour a dingy brown; but the case was all along a very hopeless one. On post-mortem examination, within the stomach, the mucous membiane at the car. diac extremity was thickly studded with minute red spots of petechire, in patches of the size of a rupee. No indications of in. testinal disease are so little understood as those of the tongue; yet none appear to merit so much study, from their eminent importance. Even the French pathologists, who take the lead in researches of this sort Andral, Martinet, and Rostan, deal but in generalities in describing its morbid state I do not remember any mention of this highly varnished dry-brown tongue by Dr. Abercrombie. Nowhere, indeed, do I find any mention of this tongue, which I have seen repeatedly, and have heard Mr. Twin. ing speak of, as indicating mnco-jejunal inflammation. In the only two cases presenting it which $I$ have had an opportunity of examining after death, there existed the petechial state of the mucous membrane of the stomach abore described; the result ap. parently of low chronic infiammation in debilitated subjects, and weakened ressels. 
Deformity succeening Burss of the much phlorizine, chrystallized, as in the ARM.- Performing the operation for their removal by a single incision camnot remedy this deformity to any great extent, as it will be almost impossible to prevent the cicatrix from again contracting as the wound heals. The operation I now detail will answer better than either of those proposed by $\mathrm{Du}$ puytren and Mr. Roberts, of Bangor. Make two incisions, so close to the arm and forearm as to include a portion of the normal integuments of both. An incision of this description giving to the excised part a triangular form, a good deal of blood necessarily flows, but it is easily restrained by pressure. By this mode the arm is brought immediately to nearly its natural form, and the wound, while healing, is much less disposed to contract. Lint smeared with a little simple ointment to the raw surfaces is to be used, and two fracture splints, on the arm and fore-arm, are to be applied, with moderate pressure. 'That portion of the treatment on which depends the success of the operation, consists in keeping up a proper extension by suspending from the wrist a weight, of at first $1 \frac{1}{2}$ pound, and increasing the weight as the cure proceeds; at the sume time binding at the wrist and top of the shoulder an elastic piece of bamboo band, drawing with a bandage the centre of it towards the bend of the arm; this is of much consequence, as it forms an antagonist power to the flexors, which the patient, to receive temporary relief from the suspended weight, constantly throws into action. Two cases which $I$ treated in this manner have succeeded quite to my satisfaction; one of them, a robust jail prisoner, who received the injury eight years since, the other a delicate boy, aged 14 years, whose defornity was of four years' standing. - D r. T . Chapman, of Purneah, in the Indian Medicul Journul, Vol. I., No. 4, N. S.

Sunstrtutes for Qunine.-M. de Koninck, a Belgian, has discovered anew medication, which he calls phlorizine; it is an extract from the bark of the apple tree. In a pipkin, fresh bark of the roots of apple trees are covered with water, and left to simmer for five hours; then strain, and put the same quantity of water again on the bark; simmer an hour or two; then strain while hot, and leave it in different vessels for 36 hours; a great quantity of phlorizine is then at the bottom, and on the sides of the vessel there is a sort of granite, more or less dark. Collect and dissolve it, and let it chrystallize several times; it is then quite purified. Or, pour weak spirits of wine over fresh bark; expose to the air for eight hours, in a temperature of $60 \mathrm{deg}$. This operation is to be performed once or twice, the liquor is mixed and distilled, and thus the greatest part of the alcohol is retained. Leave the drugs to cool, and on the next day there is first process, but much clearer. At the hospital in Brussels, from 10 to 1.4 grains, with a drachm of sugar, in one dose, given for intermittent fever, derived the most marked success where quinine had failed. Dr. Pott has also long employed parsley juice in intermittent fevers, as a powerful febrifuge, instead of quinine. The juice is extracted thus:-Chop and then pound a handful of fresh parsley, pour an ounce of water over it; pound it again; pour the whole on a wet linen rag, and then wring out the sap over a vessel. Three ounces to be taken at two different times, a few hours before the fever comes on. Intermittents not cured by quinine have been completely so by this remedy. It has been prescribed in various other diseases, and although nearly erased from the pharmacopocia, Dr. Pott's observations may perhaps restore it to favour.Con. and Brit. Medical Revieu.

Ergot of Rye in Protracted Labolr.Five cases of protracted labour, \&c., in which the ergot of rye was successfully given, are published by Mr. Raleigh, in the India Med. Jour. for 1836. We extract the following case, (the second) in which the operation of the ergot was well marked :I was called to sec a young woman, aged 17 , who had been 36 hours in labour, her first continement; the European nurse, although a skilful midwife, was in great alarm. The pains, which had at first been severe and frequent, had for several hours entirely ceased; the patient was deadly pale, and much exhausted, with a feeble pulse, and skin suffused with perspiration. I found the os uteri dilated, the membrane protruding in a pointed form, and the feet presenting with the toes turned towards the pubis of the mother. A scruple of the ergot had no effect; half an hour afterwards, a second dose occasioned a slight return of nterine contraction; I gave a third scruple-dose after a second half-hour had elapsed, fifteen minutes after which, vomiting ensued, the membranes busst, and labour advanced uuaided; the thighs came into the vagina, when $I$ turned the child to bring its face towards the sacrum; the labour proceeded naturally, and mother and child did well.

Operation of Empyema.- M. Recamiel considering hectic fever after empyema as, the result of alteration in the pus, by its mixture with external air, advises, immediately after the evacuation of the liquid, to inject into the chest water (temperature $28^{\circ}$ R.), sufficient to occupy the place that the external air would fill. M. Recamier did not find this water in the pleura greatly affect a patient in whom he has emplosed it; but the plan is based on an improved supposition, and is of doubtful propriety. 
M. Chomel's Treatment of Rheumatism. -M. Chomel, who has made rheumatism his constant study, considers gout and rheumatism one and the same disease. What is his treatment of a malady on which there are so many different opinions? In articular and acute rheumatism, this able practitioner considers the following as rational treatment :-

In the young and robust, bleeding, employed once or twice, is very desirable, to abate the febrile action, to diminish the inflammation in the articulations, and to prevent metastasia. But the bleeding must not be renewed, for weakness disposes the patient to a relapse.

Local bleedings are less desirable than phlebotomy, in articular febrile rheumatism, the disease evidently being general, fre. quently constitutional. Though they relieve one articulation, the pain may arise elsewhere, and the patient might be destroyed in pursuing the disease, as it flies from one part to another. Yet if the articulation be a prey to intense pain, and there be convulsive motions in the adjoining muscles, local bleeding is then absolutely necessary, even at the risk of weakening the patient, and leeches are more advisable than cupping, which renders the pain almost unbearable. It is generally advisable to apply soothing plasters to the affected articulations, but rheumatism is sometimes attended with such great heat, that it would be wrong to stop the diminution of caloric by any topical application. But when the articulations feel cold, poultices are indispensable.

Warm baths are advisable in all inflammatory cases, though in rheumatic fever removal from the bed to the bath, and back again, is always inconvenient, and sometimes impracticable. Where there is perspiration, baths must not be employed, as the patient is then in a natural bath. Another contra-indication is the fear of cold, either in the bath or on leaving it, and then more harm than good is done.

The drink should be cooling; warm beverage increases the perspiration and heat, without producing nitimate benefit. If there be fear of cold drink, only half a glass every quarter of an hour should be taken. This will gradually diminish the perspiration without danger, and the urinary excretion will be increased instead. Whey is generally recommended. The bed should not be too soft. Elevate the articulations, that the liquids may pass freely. The diet not too low. At the commencement, whey, gruel, fruit, vegetables; when the fever is abated, jellies, red fruit, \&c.

Vapour baths powerfully tend to terminate the disease. If any complications arise, immediately combat them.

These rules of $M$. Chomel only concern the treatment of acute articular rheumatism, not its attacks on the muscular tissue or viscera, which, in the opinion of uunterous practitioners, it sometimes invades.

Caution hespecting the Numerical MeTHOD.-In 1774 Stoll was appointed to the hospital of the Santa Trinité, and found the register kept by his predecessor during fourteen years. This register indicated each year the general mortality, and the mortality of malignant fever during twelve years. In 1769 the hospital lost in malignant fever, 1 in $3 \frac{1}{2}$. In 1772,1 in 11 , the medium being 1 in 7 . Referring to such facts as these, at a late meeting of the Academy of Medicine in Paris, M. Bousquet concluded that too much importance should not be given to the minute calculations of medical statistics, lest they should prevent the practitioner from studying the particular case which he is treating.

Typhus Fever,-Purgatives,-Bleeding in Typhus, and other Diseases.-The result of Andral and Louis's observations, lately communicated in Paris, are as fol. lows :-

1st. Purgatives are not as dangerous in typhus fever as they are represented to be. That in no case in which they were given at the commencement of typhoid fever have they increased the disease.

2nd. That in serious cases, purgatives have produced more advantageous results than bleeding, or the mixed method.

3rd. That in all cases indiscriminately treated by aperients only, the mortality has been less than by bleeding.

M. Andral said, that he had frequently had recourse to bleeding, in his own practice, for patients in typhoid fever, and that the patients had died rapidly, in a species of sub-delirium. When the illustrious Broussais was the leading man in the Paris medical schools, M. Andral says, "I had innumerable opportunities of attending students attacked with the typhoid fever. Those young men, acquainted with the prevailing doctrines, had insisted on being bled copiously, before I saw them. I bled them again, according to their constitution. Most of these unhappy patients sank and died. It is not, therefore, surprising that I should have conceived so great an aversion for bleeding in typhoid fever. I conscientiously assert, indeed, that $I$ have also seen the most distressing results ensue from copious bleeding in other diseases. In erysipelas, for instance, under the influence of bleeding, the skin has become white, but phlogosis has still existed in the subcutaneous cellular tissue ; and the patients gradually sank and died. I have observed the same phenomena in several cases of pneumonia, though I do not mean to say, that bleeding should be totally avoided in erysipelas and pneumonia, but the modus in rebus should be observed." 
SAlt and Water, to Quench Thipst, AND Allay Vouiting.-Mr. Chapman, in the treatment of cholera, has administered common salt in solution in several cases, apparently with considerable advantage. Mr. Corbyn also has mentioned, that he allowed his patients to drink freely of congee water abounding with salt, observing, that it tended to act on the bowels, and he did not find that it aggravated thirst, an effect to be apprehended from its use. Without discussing the probable action of the remedy, I shall merely state a fact which occurred in ny own practice, neither of the above gentlemen, so far as I have seen, having distinctly described what the advantages of the salt were. In May, 1835, a sepoy of the resident's escort was attacked with spasmodic cholera. I need not describe the case minutely; excessive thirst, and heat at the pit of the stomach, formed part of the symptoms, and his calls for cold water were urgent and incessant. $\mathrm{He}$ vomited every thing as soon as swallowed. I had lately been readin ${ }^{*}$, that English medical men had tried common salt, and independently of its praises as an emetic, I saw a solution of it recommended for the dreadful thirst, and burning at the precordia. Determining to try it, I put four large table-spoonfuls of salt to a wine bottle of cold water, of which I gave a table-spoonful every three or four minutes. The first two doses were rejected, but before half a dozen doses were taken, the patient was relieved. I then repeated the scruple doses of calomel and opium, which $I$ had at first given; these were now retained, and I continued the salt and water, at the man's urgent request. At length the gastric symptoms subsided, and it was not until he had taken nearly the whole of the salt and water that he discovered its saline taste. He slept, and rapidly recovered. The case is interesting, and may be useful, as regards the effect of the salt and water in relieving the burning thirst, quieting the stomach, and enabling it to retain other remedies, to an extent which was surprising to myself and all the attendants. I do not think it acted on the bowels, and I am sure it did not create thirst, either at the time, or afterwards.-Mr. T. G. BAYfiELD, Ava, in the India Hed. Jour.

Post-mortem Reputation.-Signion Segato, whose extraordinary preparations of the human body, and other animal substances, to suspend their decay, excite-. much curiosity, died lately at Florenced His secret perished with him. His death is said to have been hastened by vexation at the refusal of the Florentine government to assist him in his undertaking. Now, how. ever, so high a value is set by that government on the preparations which he has left, that they have formally prohibited their removal from the country.-Mag. of Popular Science, May.
Dr. Mondiereon Incontinence of Urine. -It has been said that this infrmity generally ceases at puberty, which is by no means the case, though it occasionally disappears in girls when the catamenia comes on. Moral means to cure this complaint are only salutary with idle children; they are totally useless in weakness of the sphircter of the bladder. This complaint cannot always be attributed to general debility, but rather to partial atony of the organs. Tonics cannot, therefore, have much influence on the disease, and we have seldom found a cure from their sole employment. A young lady, with whom it ceased on the day on which the catamenia appeared, had for sereral years taken wine, meat, and tonic medicaments. However, some tonics and stimulants have proved efficacious. Contharides may be safely recommended. Dr. Roth has cured it by rhatany; sub-carbonate of iron may also be employed. The patients should drink good wine, mixed with ferruginous water, and take exercise. Dupuytren was a great adrocate for cold baths. Aromatic. plant baths, employed by Lallemand, are preferable to cold baths; at least ten are requisite. We doubt the use of electricity, though it is much lauded. Cupping, blisters, and moxas, on the perineum have been successful; butmore advantage is derived from catheterism, which is strongly recommended by Baurielocque. M. Mondière chiefly advises nux vomica, 8 grains of the extract, with a drachm of oxide of iron, in 24 pills, 3 to be taken daily. - Con. and Brit. M.Rer.

Circunstances favourable and unfavourabie to Lithotrity.-These (says M. Civiale) frequently depend on the severe disorders in the urinary organs, of the general health attendant on the progress of stone in the bladder, and also on the stones. It is, therefore, necessary to consider,-

ist. The size, strength, and situation in the bladder of the stone, whether it be free and floating, or adherent; and the number of stones.

2nd. The state of the bladder, prostate, urethra, and kidneys.

3rd. The general state of the patient.

The diseases, thus classed, may again bo divided into four series:- The first comprises the most facourable cases,-only one stone, of middling size, friable, even, hard, with a healthy bladder, the urethra free, anda good constitution.

The second series offers conditions much less advantageous, but which principally depend on the size and number of the stones. The treatment then demands greater length of time, and more precaution. In this series the stone is large and hard, or else there is much gravel, the bladder nearly healthy.

The cases comprised in the third series are unfayourable; yet do not quite repel 
lithotrity, which succeeds when proper attention is paid to the evil disposition of the organs. It will then be well to make one or two trials, not injurious to cystotomy, if at last that be necessary.

In a fourth series we must place the cases for which lithotrity is generally contra-indicated; a single stone, but voluminous and hard, quantity of gravel of middling size, encysted stone, horny bladder, bloody, and very painful; prostate hypertrophied, painful, strong deviation of the urethra, persisting coarctation of long standing; urine purulent, ammoniacal ; kidneys diseased, patient irritable, weak, and worn out.

Originally, paralysis and chronic catarrh of the bladder were looked on as contra-indications of lithotrity. Experience has proved that these are not of great conse. quence in lithotrity. Most calculous patients are affected with catarrh of the bladder, more or less intense. Instead of this complication being increased by lithotrity, it improves during the treatment, and generally disappears with the principal disease.

THE EVIDENCE

RLLATING TO THE

MEDICAL RELTEF OF THE SICK POOR IN THE PAROCHIAL UNIONS,

GIVEN BLFORE THE.

\section{SELECT COMMITTEE OF THE HOUSE} OF COMMONS, IN 1837.

\section{TENTII DAY.}

Wednesday, April 14.

Mr. Fazakerley in the Chair.

\section{Mr. Thomas Bourne.}

4324. Examined by the Chatrman.] You are master of the Fareham workhouse?Yes.

4328. In what state were the boys Cooke, Warren, and Withers, when they were sent to you ?-They appeared healthy.

4330. Who is the medical man of that Louse ?-Mr. Johu Blatherwick.

4332. Had those children dirty habits ?They commenced their dirty habits the first or second night after their admission.

1334. What observation did the medical man make upon hearing of that?-None in particular.

4336. What did you do to correct those habits? -Withheld part of the food.

4342. Were the visiting guardians made acquainted with the food being diminished? -Yes, they did not object to it. Half of the food for the day was stopped.
4348. Was any punishment also had 1ecourse to?-The children were placed in the stocks frequently, both standing and sitting, and were kept in them from meal to meal, at the same time that their food was diminished, I believe. When the schoolmis. tress intimated to me that it did not appear to have any effect upon their filthy habits, I desired her to discontinue withholding their food, or any other punishment.

4359. How soon afler they were in the house did the schoolmistress observe to you that their health appeared to decline ? ${ }^{I}$ suppose a month.

4362. Did you communicate it to the medical officer?-Yes, he saw them; he did not direct anything; they were obliged to be put to bed in consequence of their dirty habits.

4365. Do you mean to say, that those circumstances being made known to the medical man he gave no directions as to their diet or general treatment?-None at all; he said he could give no sort of medicine for it. About ten days before they were removed to Droxford again they were, by the order of the medical man, removed to an out-building, in consequence of their filth, that it should not affect the health of other chlldren.

4392. Are you aware of a resolution passed by the Board of Gurdians on the subject, of this nature: "Farehan Union, 3rd of March, 1837. Resolved, that the master of the workhouse has not used a sound discretion in so extensively and re. peatedly reducing the food of the three children in question, without specially reporting to the Board"?-Yes.

4400. $B y \mathrm{Mr}$. Gondon.] Were there many other children whose food was diminished? - Yes ; it was very frequent for beds to be dirted and wet amongst so many children, and it was the custom to diminish the quantity of their food.

4402. Have you ever known illness produced from the food being diminished ?No; the visiting committee, or such part of it as did visit, were acquainted with the diminution, and they did not object to that mode of panishment.

4419. By Mr. Walter.] Were those children beaten also?-I have done it once or twice with a small birch rod.

4420. Have any of the paupers beaten them ?-I do not know.

4421. Recollect? - One of the girls, Susan Axford, had beaten one of them.

4428. Did any of the guardians ever see the children in the stocks?-Yes.

4429. Did the chaplain?-Yes. The chaplain is Sir Henry Thompson, Bart.

4437. Did the porter ever punish any children?-I complained of him to the Board for severity which I had heard it was general for him to use. He superintended, with his wife, in the school. 